12

\title{
Синтез кластеров оксидов железа в мезопорах монодисперсных сферических частиц кремнезема
}

\author{
( Е.Ю. Стовпяга ${ }^{1}$, Д.А. Еуров ${ }^{1}$, Д.А. Курдюков ${ }^{1,2}$, А.Н. Смирнов ${ }^{1}$, М.А. Яговкина ${ }^{1}$, \\ B.Ю. Григорьев ${ }^{3}$, В.В. Романов ${ }^{3}$, D.R. Yakovlev', В.Г. Голубев ${ }^{1}$
}

${ }^{1}$ Физико-технический институт им. А.Ф. Иофффе РАН,

Санкт-Петербург, Россия

${ }^{2}$ Санкт-Петербургский национальный исследовательский университет

информационных технологий, механики и оптики,

Санкт-Петербург, Россия

${ }^{3}$ Санкт-Петербургский политехнический университет Петра Великого,

Санкт-Петербург, Россия

${ }^{4}$ Experimentelle Physik 2, Technische Universität Dortmund,

Dortmund, Germany

E-mail: kattrof@gvg.ioffe.ru

(Поступила в Редакцию 12 декабря 2016 г.)

\begin{abstract}
Предложен метод получения нанокластеров $\alpha-\mathrm{Fe}_{2} \mathrm{O}_{3}$ в порах монодисперсных сферических частиц мезопористого кремнезема $\left(\mathrm{mSiO}_{2}\right)$ путем однократной пропитки пор расплавом кристаллогидрата нитрата железа и его последующей термодеструкции. Восстановлением в термодинамически равновесных условиях из $\alpha-\mathrm{Fe}_{2} \mathrm{O}_{3}$ в порах синтезированы нанокластеры $\mathrm{Fe}_{3} \mathrm{O}_{4}$. Затем частицы, содержащие $\mathrm{Fe}_{3} \mathrm{O}_{4}$, были отожжены в кислороде для превращения $\mathrm{Fe}_{3} \mathrm{O}_{4}$ обратно в $\alpha-\mathrm{Fe}_{2} \mathrm{O}_{3}$. В результате получены частицы со структурой ядро-оболочка $m \mathrm{SiO}_{2} / \mathrm{Fe}_{3} \mathrm{O}_{4} @ m \mathrm{SiO}_{2} / \alpha-\mathrm{Fe}_{2} \mathrm{O}_{3}$. Исследованы состав и структура синтезированных материалов, а также полевая зависимость магнитного момента от напряженности магнитного поля.
\end{abstract}

Работа выполнена при финансовой поддержке РФФИ (проект № 15-52-12011) и DFG в рамках ICRC TRR 160.

DOI: 10.21883/FTT.2017.08.44764.439

\section{1. Введение}

Магнитные нано- и микрочастицы оксидов железа имеют широкий спектр применения в катализе, магнитной сепарации, в качестве биологических сенсоров и адсорбентов для очистки воды от тяжелых металлов [1-3]. Наночастицы магнетита $\left(\mathrm{Fe}_{3} \mathrm{O}_{4}\right)$, гематита $\left(\alpha-\mathrm{Fe}_{2} \mathrm{O}_{3}\right)$ и маггемита $\left(\gamma-\mathrm{Fe}_{2} \mathrm{O}_{3}\right)$ благодаря низкой токсичности и биосовместимости интенсивно исследуются для применения в биомедицине в качестве $T_{2}$ контрастных средств для магнитно-резонансной томографии (МРТ) [4] и магнитной гипертермии [5]. Намагниченность и магнитная анизотропия наноразмерных однодоменных частиц могут быть заметно больше, чем у массивного материала, а отличия в температурах Кюри и Нееля достигают сотен процентов. У магнитных наночастиц обнаружены высокие значения обменного взаимодействия и аномально большой магнитокалорический эффект [6,7].

Наночастицы оксидов железа размером менее $100 \mathrm{~nm}$ агрегативно неустойчивы, что обусловлено их магнитным взаимодействием друг с другом. Это затрудняет масштабное практическое применение частиц в медицине и катализе. Для использования частиц оксидов железа в катализе и в качестве электрохимических сенсоров было предложено размещать частицы (нанокластеры) в пористых носителях, например, заполнять подсистему цилиндрических мезопор кремнезема типа MCM-41 водными растворами солей железа $\left(\mathrm{FeCl}_{3}\right.$,
$\left.\mathrm{Fe}\left(\mathrm{NO}_{3}\right)_{3}\right)$ или вводить соли железа в процессе гидротермального синтеза МСM-41, с последующим термическим разложением для формирования оксидных нанокластеров [8-10].

Другим способом решения проблемы агрегативной неустойчивости магнитных частиц и сохранения их магнитных характеристик является покрытие их оболочками из немагнитного материала, в частности, наночастицы оксидов железа покрывают оболочкой кремнезема различной толщины [11]. Кремнезем имеет ряд преимуществ перед органическими оболочками, например, он менее подвержен биодеградации [12]. Покрытие частиц оболочкой кремнезема позволяет сохранять их индивидуальные магнитные свойства и легко контролировать взаимодействие частиц между собой в суспензиях, что обеспечивает агрегативную устойчивость водных коллоидных растворов в широком диапазоне значений $\mathrm{pH}$ [13]. Альтернативным подходом к получению ансамблей изолированных магнитных нанокластеров является их синтез внутри темплатов из немагнитного материала, обладающих пространственно-периодической структурой монодисперсных пор, например, в порах искусственных опалов [14].

Магнитные наночастицы также покрывают различными магнитными оболочками, что позволяет изменять физические свойства частиц $[15,16]$. В работе [17] показано, что в частицах, состоящих из ядра $\mathrm{Fe}_{x} \mathrm{O}$ 
диаметром $3 \mathrm{~nm}$, покрытого ферримагнитной оболочкой $\mathrm{Fe}_{3} \mathrm{O}_{4}$ толщиной $3.5 \mathrm{~nm}$, при $x \sim 0.80$ ядро не обладает магнитными свойствами, а при $x \sim 0.95$ ядро становится антиферромагнитным. Авторы работы [15] описали методику получения частиц ядро-оболочка со структурой $\mathrm{Fe}_{3} \mathrm{O}_{4} @ \alpha-\mathrm{Fe}_{2} \mathrm{O}_{3}$ диаметром $\sim 50 \mathrm{~nm}$ и продемонстрировали изменение свойств от ферромагнитных к суперпарамагнитным после того, как поверхность исходных частиц $\mathrm{Fe}_{3} \mathrm{O}_{4}$ была окислена до $\alpha-\mathrm{Fe}_{2} \mathrm{O}_{3}$. Кроме того, покрытие магнитных наночастиц магнитной оболочкой позволяет плавно регулировать теплоотвод, что увеличивает эффективность применения частиц в магнитной гипертермии [16].

В настоящей работе описан метод синтеза нанокластеров $\alpha-\mathrm{Fe}_{2} \mathrm{O}_{3}$ и $\mathrm{Fe}_{3} \mathrm{O}_{4}$ в монодисперсных сферических мезопористых частицах кремнезема (МСМЧК), имеющих монодисперсные цилиндрические мезопоры. Предложен способ заполнения МСМЧК расплавом кристаллогидрата нитрата железа (III) под действием капиллярных сил. В едином технологическом цикле посредством термодеструкции $\mathrm{Fe}\left(\mathrm{NO}_{3}\right)_{3} \cdot 9 \mathrm{H}_{2} \mathrm{O}$ в порах МСМЧК синтезированы нанокластеры $\alpha$ - $\mathrm{Fe}_{2} \mathrm{O}_{3}$. Степень заполнения пор составила $30 \%$ vol. Методом термодинамически контролируемого восстановления из $\alpha$ - $\mathrm{Fe}_{2} \mathrm{O}_{3}$ внутри пор МСМЧК получены изолированные нанокластеры $\mathrm{Fe}_{3} \mathrm{O}_{4}$. На последнем этапе МСМЧК, содержащие $\mathrm{Fe}_{3} \mathrm{O}_{4}$, были отожжены в потоке кислорода, что позволило получить частицы со структурой ядро-оболочка. Поры в глубине МСМЧК были заполнены нанокластерами $\mathrm{Fe}_{3} \mathrm{O}_{4}$, а поры, находящиеся вблизи внешней поверхности частиц, содержали $\alpha-\mathrm{Fe}_{2} \mathrm{O}_{3}$. Структура синтезированных нанокомпозитов исследована методом рентгеновской дифракции и рамановской спектроскопии. Изучены магнитные свойства полученных материалов.

\section{2. Методика эксперимента}

Монодисперсные сферические мезопористые частицы кремнезема синтезированы согласно ранее разработанной методике $[18,19]$. В статье приведены результаты для МСМЧК диаметром $200 \mathrm{~nm}$. Частицы имеют сферическую форму, среднеквадратичное отклонение размеров частиц не преваышает 6\%. Внутри МСМЧК имеется подсистема плотноупакованных пор диаметром $3.1 \mathrm{~nm}$. Объемная доля пор составляет $\sim 50 \%$ vol. от объема частиц.

Нанокластеры $\alpha-\mathrm{Fe}_{2} \mathrm{O}_{3}$ синтезированы в мезопорах МСМЧК посредством капиллярной пропитки [20] расплавом кристаллогидрата $\mathrm{Fe}\left(\mathrm{NO}_{3}\right)_{3} \cdot 9 \mathrm{H}_{2} \mathrm{O}$ и его последующего разложения. Методика заполнения МСМЧК расплавами описана в работе [21]. К расплаву добавляли навеску частиц, затем проводили отжиг для разложения нитрата при $250^{\circ} \mathrm{C}$ до $\alpha-\mathrm{Fe}_{2} \mathrm{O}_{3}$ в течение $2 \mathrm{~h}$. Нанокластеры магнетита синтезировали в порах МСМЧК восстановлением гематита водородом в термодинамически равновесных условиях, аналогично методике, описанной в работе [22]. В качестве газа-носителя использовали аргон. Парциальное давление $\mathrm{H}_{2}$ было равно $0.2 \mathrm{bar}$. Температура отжига составляла $350^{\circ} \mathrm{C}$. Затем магнетит вновь окисляли при температуре $700^{\circ} \mathrm{C}$ в течение $20 \mathrm{~h}$ для получения $\alpha-\mathrm{Fe}_{2} \mathrm{O}_{3}$ в порах вблизи внешней поверхности частиц.

Степень заполнения пор МСМЧК гематитом определялась по значению плотности частиц, рассчитываемой из уравнения Стокса. Необходимое для расчета значение скорости седиментации диспергированных в воде частиц измерялось экспериментально.

Фазовый состав нанокомпозитов определялся рентгенодифракционным методом на установке Bruker D2 Phaser (использовалась линия $\mathrm{Cu} K \alpha$ ). Рамановские спектры исследовались при комнатной температуре на спектрометре Horiba Jobin Yvon T64000 с использованием в качестве источника излучения второй гармоники Nd:YAG-лазера $(\lambda=532 \mathrm{~nm})$, плотность возбуждения на поверхности образца не превышала $P=2 \mathrm{~kW} / \mathrm{cm}^{2}$.

Изучение магнитных свойств нанокомпозитов проводилось путем анализа полевых зависимостей магнитных моментов образцов, измеренных методом Фарадея при комнатной температуре с дискретной разверткой внешнего магнитного поля на установке, созданной на базе спектрометра MGD 312 FG. Калибровка установки проводилась с помощью эталонного образца, в качестве которого использовался монокристалл магнитно-чистого фосфида индия с восприимчивостью $\chi=-313 \cdot 10^{-9} \mathrm{~cm}^{3} / \mathrm{g}$. Масса образца определялась на весах BP $211 \mathrm{D}$ с точностью до $10^{-5} \mathrm{~g}$. Подробно методика эксперимента описана в работе [23].

\section{3. Результаты и обсуждение}

Рассмотрим подробно методику получения нанокластеров $\alpha-\mathrm{Fe}_{2} \mathrm{O}_{3}$ и $\mathrm{Fe}_{3} \mathrm{O}_{4}$ в мезопорах. На первом этапе (рис. 1, $a$ ) осуществлялась пропитка МСМЧК прекурсором - расплавом кристаллогидрата нитрата железа (III) и проводился отжиг с целью разложения нитрата до $\alpha-\mathrm{Fe}_{2} \mathrm{O}_{3}$. В качестве прекурсора был выбран расплав кристаллогидрата, а не раствор, поскольку в расплаве выше содержание целевых элементов - $\mathrm{Fe}$ и $\mathrm{O}$ [21]. Процесс образования нанокластеров оксидов железа в порах можно представить следующим образом (рис. 1). Первоначально поры МСМЧК заполняются расплавом $\mathrm{Fe}\left(\mathrm{NO}_{3}\right)_{3} \cdot 9 \mathrm{H}_{2} \mathrm{O}$ вследствие капиллярного эффекта. При нагревании происходит терморазложение жидкого кристаллогидрата по следующей схеме: $\mathrm{Fe}\left(\mathrm{NO}_{3}\right)_{3} \cdot 9 \mathrm{H}_{2} \mathrm{O} \rightarrow \mathrm{Fe}(\mathrm{OH})\left(\mathrm{NO}_{3}\right)_{2} \rightarrow$ $\mathrm{Fe}(\mathrm{OH})_{2} \mathrm{NO}_{3} \rightarrow \mathrm{FeO}(\mathrm{OH}) \rightarrow \alpha-\mathrm{Fe}_{2} \mathrm{O}_{3}$ [24]. Газообразными продуктами реакций являются $\mathrm{NO}_{2}, \mathrm{O}_{2}, \mathrm{H}_{2} \mathrm{O}$.

Мольный объем материала в порах при терморазложении кристаллогидрата сильно уменьшается. Поскольку мольные объемы $\mathrm{Fe}\left(\mathrm{NO}_{3}\right)_{3} \cdot 9 \mathrm{H}_{2} \mathrm{O}$ и $\alpha$ - $\mathrm{Fe}_{2} \mathrm{O}_{3}$ при $20^{\circ} \mathrm{C}$ на один атом $\mathrm{Fe}$ равны соответственно 246.3 и $15.2 \mathrm{~cm}^{3} / \mathrm{mol}$, максимально возможная расчетная степень заполнения МСМЧК $\alpha-\mathrm{Fe}_{2} \mathrm{O}_{3}$ за один цикл пропитки 

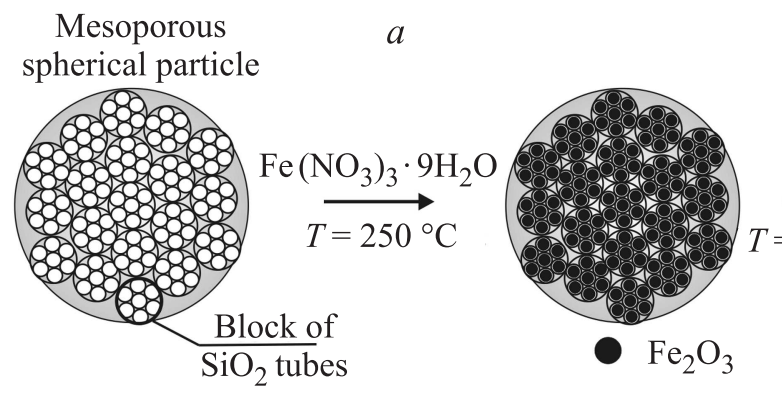

$b$

$c$
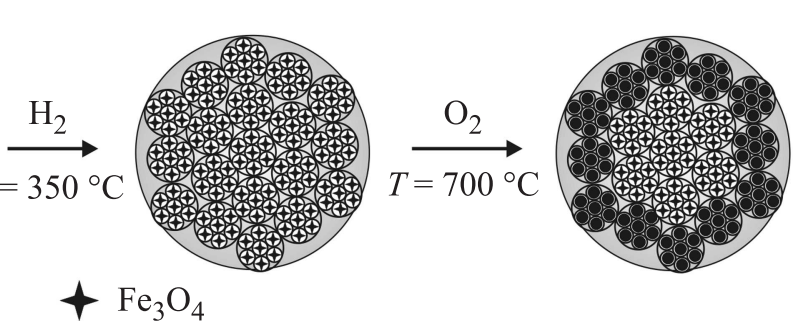

Рис. 1. Схема заполнения МСМЧК оксидами железа: (a) Капиллярная пропитка МСМЧК расплавом $\mathrm{Fe}\left(\mathrm{NO}_{3}\right)_{3} \cdot 9 \mathrm{H}_{2} \mathrm{O}$ и

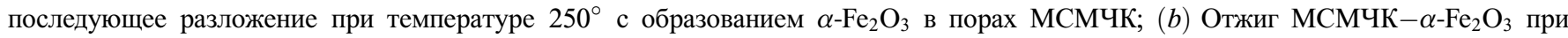

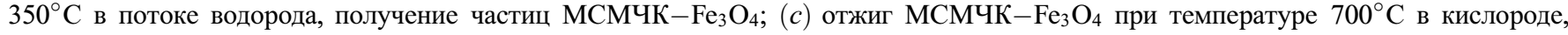
получение частиц ядро-оболочка $m \mathrm{SiO}_{2} / \mathrm{Fe}_{3} \mathrm{O}_{4} @ m \mathrm{SiO}_{2} / \alpha-\mathrm{Fe}_{2} \mathrm{O}_{3}$.

составляет $\sim 6 \%$ от объема пор. В то же время экспериментально определенное значение степени заполнения пор МСМЧК $\alpha-\mathrm{Fe}_{2} \mathrm{O}_{3}$ составило $30 \%$ от объема пор. Ранее [21,25] было показано, что увеличивать степень заполнения пор (вплоть до полного) оксидами $d$ - и $f$-элементов можно, изменяя время контакта частиц с расплавом кристаллогидрата. При этом происходит постоянная „подпитка“ пор расплавом, который, в свою очередь, разлагается до оксида, благодаря чему объем наполнителя в порах снова уменьшается. Затем расплав вновь заполняет поры и т.д. Расплавный метод заполнения мезопор исключает присутствие массивного вещества на внешней поверхности частиц [21,25]. При полном заполнении пор оксидом происходит формирование нанонитей, диаметр которых равен диаметру пор в темплате [26,27]. В настоящей работе время контакта частиц с кристаллогидратом (2h) было достаточным для „подпитки“ незаполненного объема пор расплавом, поэтому заполнение пор было больше расчетного значения. Массы навесок МСМЧК и $\mathrm{Fe}\left(\mathrm{NO}_{3}\right)_{3} \cdot 9 \mathrm{H}_{2} \mathrm{O}$ были выбраны таким образом, чтобы после отжига гематитом было заполнено не более $30 \%$ от общего объема мезопор в частицах.

Описанная технологическая схема, вероятно, приводит к формированию в порах МСМЧК изолированных кластеров $\alpha-\mathrm{Fe}_{2} \mathrm{O}_{3}$ сферической или продолговатой формы. На формирование нанокластеров $\alpha-\mathrm{Fe}_{2} \mathrm{O}_{3}$ при термодеструкции $\mathrm{Fe}\left(\mathrm{NO}_{3}\right)_{3} \cdot 9 \mathrm{H}_{2} \mathrm{O}$ влияют: 1) значительное уменьшение мольного объема наполнителя; 2) большое газовыделение. Во-первых, если цилиндрическая мезопора полностью заполнена расплавом, то при его разложении объем вещества в этой поре уменьшится приблизительно в 15 раз (см. выше) и образуются один или несколько кластеров, диаметр которых равен диаметру поры и в то же время в несколько раз меньше ее длины. Во-вторых, объем выделяющихся газообразных продуктов (при нормальных условиях) на 3-4 порядка превышает объем расплава кристаллогидрата, что также влияет на процесс разложения расплава и на распределение наполнителя в порах. Массоперенос газов в порах синтезированных частиц определяется особенностями их внутренней структуры. МСМЧК состоят из блоков плотноупакованных трубок кремнезема $[18,19]$. Между блоками имеются транспортные поры размером 3-7 nm [28]. Газообразные продукты будут преимущественно выходить наружу через поры наибольшего диаметра. Капиллярное (лапласово) давление расплава в цилиндрических трубках $m \mathrm{SiO}_{2}$ диаметром $3 \mathrm{~nm}$ составляет примерно $1000 \mathrm{bar}$, что, вероятно, больше давления газообразных продуктов, выходящих через транспортные мезопоры. Поэтому выделяющиеся газы не могут вытолкнуть жидкость из трубок $\mathrm{mSiO}_{2}$, и кристаллогидрат, разлагаясь, образует внутри них нанокластеры гематита. Ранее при аналогичном терморазложении нитратов и органосиланов в макропорах синтетических опалов и мезопорах МСМЧК были получены изолированные нанокластеры $\mathrm{NiO}, \mathrm{Co}_{3} \mathrm{O}_{4}, \mathrm{NiCo}_{2} \mathrm{O}_{4}$ и углерода $[23,29]$.

Наличие в порах МСМЧК гематита подтверждено методами рентгенофазового анализа (РФА) и рамановской спектроскопии. По данным РФА (рис. 2, кривая 2) для МСМЧК, содержащих $\mathrm{Fe}_{2} \mathrm{O}_{3}$, наблюдается набор дифракционных рефлексов, соответствующий орторомбическому $\alpha-\mathrm{Fe}_{2} \mathrm{O}_{3}$ (рис. 2, кривая 1). Исследование этого материала методом рамановской спектроскопии показало наличие в спектрах раман-активных фононных мод симметрии $A_{1 g}$ и $E_{g}$, характерных для гематита (рис. 3, кривая 1) [30]. Слабая полоса на частоте $\sim 826 \mathrm{~cm}^{-1}$ соответствует магнонной моде $M$ [31]. Также в спектре наблюдается интенсивная широкая полоса с максимумом на частоте $\sim 1322 \mathrm{~cm}^{-1}$, соответствующая фононному спектру второго порядка $(S O)$ [32].

На втором этапе (рис. $1, b)$, МСМЧК, заполненные $\alpha-\mathrm{Fe}_{2} \mathrm{O}_{3}$, отжигали в потоке водорода при $350^{\circ} \mathrm{C}$ до полного перехода $\alpha$ - $\mathrm{Fe}_{2} \mathrm{O}_{3}$ в $\mathrm{Fe}_{3} \mathrm{O}_{4}$. Согласно расчету равновесного состава смеси [22], превращение гематита в магнетит осуществляется при парциальном давлении водорода $0.2 \mathrm{bar}$, парциальном давлении водяного пара $10^{-4}$ bar и общем давлении 1 bar при температурах до $380^{\circ} \mathrm{C}$. При этом равновесное количество твердофазных примесей составляет менее $0.01 \% \mathrm{~mol}$. По литературным данным [33], железо со степенью 


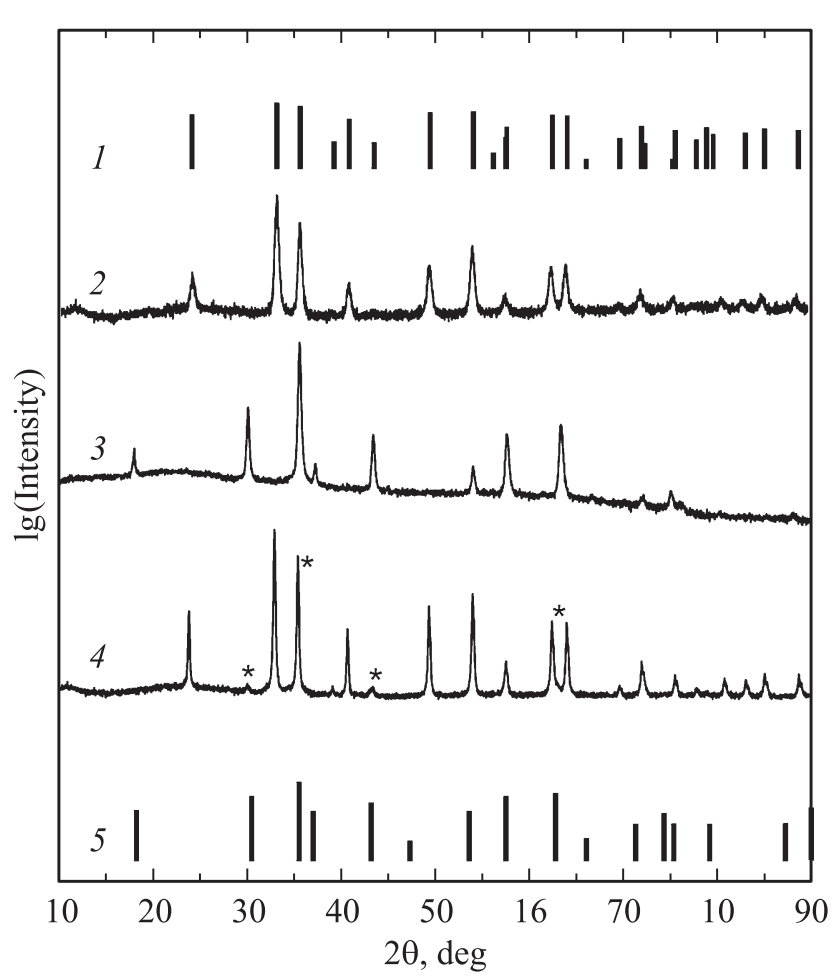

Pис. 2. Дифрактограммы: $1-\alpha-\mathrm{Fe}_{2} \mathrm{O}_{3}$ (JCPDS 84-0309), 2 - МСМЧК $-\alpha-\mathrm{Fe}_{2} \mathrm{O}_{3}, 3-\mathrm{MCMЧК-} \mathrm{Fe}_{3} \mathrm{O}_{4}, 4$ - частицы ядро-оболочка $m \mathrm{SiO}_{2} / \mathrm{Fe}_{3} \mathrm{O}_{4} @ m \mathrm{SiO}_{2} / \alpha-\mathrm{Fe}_{2} \mathrm{O}_{3}, 5-\mathrm{Fe}_{3} \mathrm{O}_{4}$ (JCPDS 75-0449). Звездочкой отмечены рефлексы магнетита.

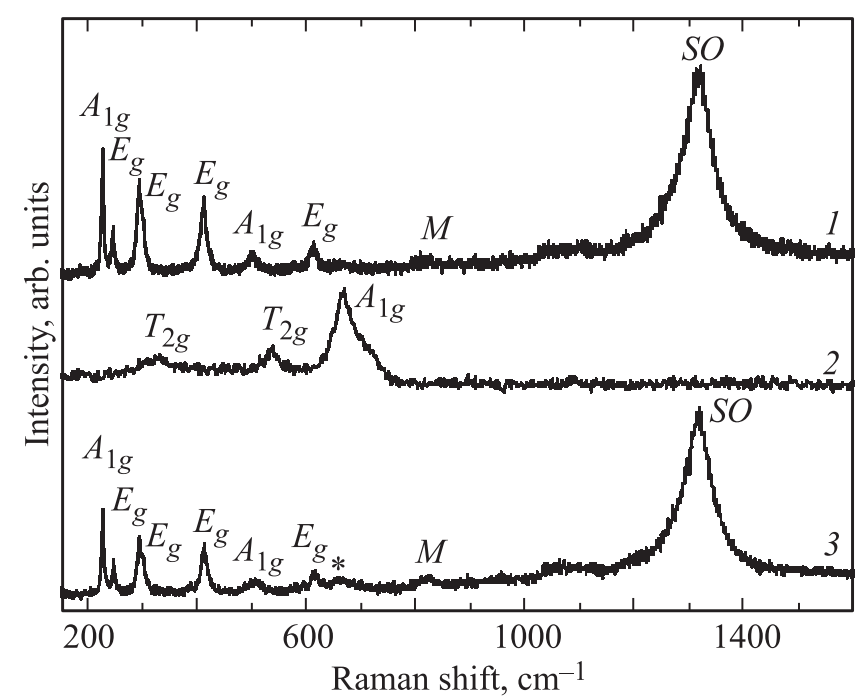

Рис. 3. Рамановские спектры: $1-\mathrm{MCMЧК}-\alpha-\mathrm{Fe}_{2} \mathrm{O}_{3}$, 2 - МСМЧК- $\mathrm{Fe}_{3} \mathrm{O}_{4}, 3-$ частицы ядро-оболочка $m \mathrm{SiO}_{2} / \mathrm{Fe}_{3} \mathrm{O}_{4} @ m \mathrm{SiO}_{2} / \alpha-\mathrm{Fe}_{2} \mathrm{O}_{3}$. Обозначены раман-активные фононные моды соответствующих оксидов. Звездочкой отмечена фононная мода $A_{1 g}$ магнетита.

окисления III не образует силикатов, а для железа со степенью окисления II есть вероятность образования при температуре свыше $1200^{\circ} \mathrm{C}$ силиката со структурой фаялита $\left(\mathrm{Fe}_{2} \mathrm{SiO}_{4}\right)$. Поскольку процесс получения $\mathrm{Fe}_{3} \mathrm{O}_{4}$ из $\alpha-\mathrm{Fe}_{2} \mathrm{O}_{3}$ является относительно низкотемпературным, образование силиката маловероятно. Кроме того, согласно расчету [22], повышение температуры приводит к образованию примесных фаз $\mathrm{FeO}$ и $\alpha$-Fe, а при температурах свыше $550^{\circ} \mathrm{C}$ реакция полностью идет до элементарного железа. Поскольку мольные объемы $\alpha-\mathrm{Fe}_{2} \mathrm{O}_{3}$ и $\mathrm{Fe}_{3} \mathrm{O}_{4}$ при $20^{\circ} \mathrm{C}$ на один атом $\mathrm{Fe}$ равны 15.2 и $14.9 \mathrm{~cm}^{3} / \mathrm{mol}$ соответственно существенного перераспределения наполнителя в порах не происходит, поэтому при восстановлении из кластеров $\alpha-\mathrm{Fe}_{2} \mathrm{O}_{3}$ образуются кластеры $\mathrm{Fe}_{3} \mathrm{O}_{4}$ той же формы и размеров. Полученный композит содержит только одну кристаллическую фазу - магнетит, что подтверждается данными РФА (рис. 2, кривая 3) и рамановской спектроскопии (рис. 3, кривая 2) [30].

На третьем этапе синтезированные частицы $\mathrm{MCMЧК}-\mathrm{Fe}_{3} \mathrm{O}_{4}$ были отожжены в потоке кислорода при давлении 3 bar и температуре $700^{\circ} \mathrm{C}$ (рис. 1,c). При окислении происходит накопление катионных вакансий в кристаллической решетке $\mathrm{Fe}_{3} \mathrm{O}_{4}$, что приводит к образованию $\alpha-\mathrm{Fe}_{2} \mathrm{O}_{3}$ [34,35]. Вероятно, процесс превращения идет в две стадии: $\mathrm{Fe}_{3} \mathrm{O}_{4} \rightarrow \gamma-\mathrm{Fe}_{2} \mathrm{O}_{3}$ и затем $\gamma-\mathrm{Fe}_{2} \mathrm{O}_{3} \rightarrow \alpha-\mathrm{Fe}_{2} \mathrm{O}_{3} \quad$ [34]. В $\alpha-\mathrm{Fe}_{2} \mathrm{O}_{3}$ железо находится в наивысшей степени окисления (III), поэтому данная кристаллическая фаза является термодинамически стабильной в кислороде. По данным РФА (рис. 2, кривая 4), основной кристаллической фазой синтезированного композита является $\alpha-\mathrm{Fe}_{2} \mathrm{O}_{3}$, однако слабые рефлексы $\mathrm{Fe}_{3} \mathrm{O}_{4}$ также присутствуют (отмечены звездочкой). В рамановских спектрах частиц МСМЧК $-\mathrm{Fe}_{3} \mathrm{O}_{4}$, отожженных в кислороде, в основном наблюдаются интенсивные фононные моды, характерные для гематита (рис. 3, кривая 3). В спектрах также видна особенность на частоте $670 \mathrm{~cm}^{-1}$, которая, вероятно, связана с фононной модой симметрии $A_{1 g}$ магнетита. Малая интенсивность этой моды относительно интенсивности фононных мод гематита может быть объяснена как малым количеством $\mathrm{Fe}_{3} \mathrm{O}_{4}$ внутри МСМЧК, так и меньшим эффективным сечением рамановского рассеяния для $\mathrm{Fe}_{3} \mathrm{O}_{4}$, чем для $\alpha-\mathrm{Fe}_{2} \mathrm{O}_{3}$.

Несмотря на продолжительный отжиг $(20 \mathrm{~h})$ в кислороде при температуре $700^{\circ} \mathrm{C}$ процесс окисления $\mathrm{Fe}_{3} \mathrm{O}_{4}$ в порах МСМЧК прошел не полностью. Ранее [22], в порах синтетических опалов полное превращение магнетита в гематит было достигнуто уже при температуре $500^{\circ} \mathrm{C}$. Мы полагаем, что внутри МСМЧК все поры в приповерхностной области частиц спустя некоторое время закрываются, и молекулы кислорода больше не могут проникать к центру частицы. Первой причиной закрытия пор может служить то, что идет перекристаллизация $\alpha-\mathrm{Fe}_{2} \mathrm{O}_{3}$ через газовую фазу с участием паров воды [36]. Массоперенос идет в направлении от центра к внешней поверхности частиц, в результате чего размер кристаллитов $\alpha-\mathrm{Fe}_{2} \mathrm{O}_{3}$ и степень заполнения пор в приповерхностной области увеличиваются. Действительно, мы наблюдаем сужение дифракционных рефлексов гематита (рис. 2, кривая 4) по сравнению с рефлексами 


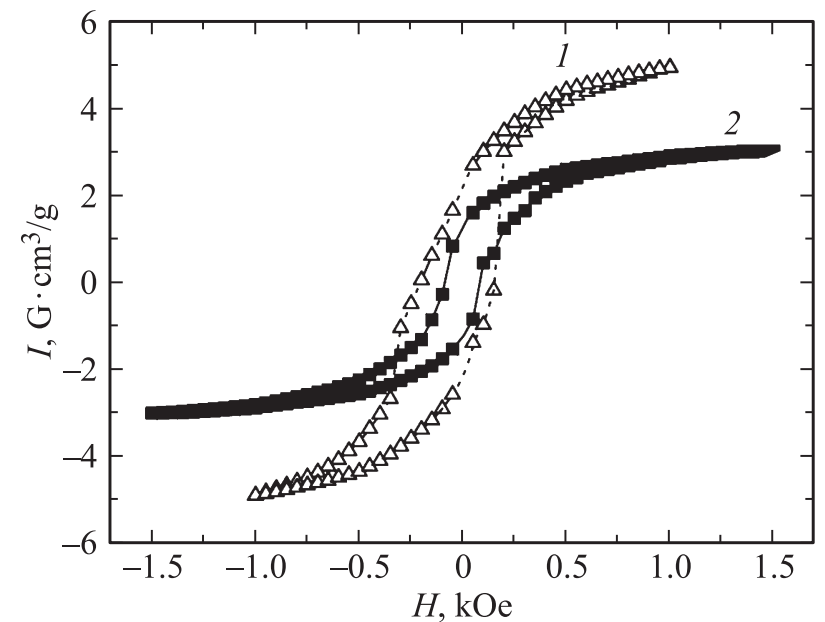

Рис. 4. Полевые зависимости магнитного момента синтезированных материалов при комнатной температуре: 1 - МСМЧК- $\mathrm{Fe}_{3} \mathrm{O}_{4}, 2$ - частицы ядро-оболочка $m \mathrm{SiO}_{2} / \mathrm{Fe}_{3} \mathrm{O}_{4} @ m \mathrm{SiO}_{2} / \alpha-\mathrm{Fe}_{2} \mathrm{O}_{3}$.

материала, полученного из кристаллогидрата на первом этапе (рис. 2, кривая 2). Второй причиной закупорки пор, вероятно, является то, что в процессе отжига при температуре $700^{\circ} \mathrm{C}$ происходит размягчение материала МСМЧК - аморфного $\mathrm{SiO}_{2}$ [37], при этом диаметр пор уменьшается и доступ кислорода к центру частиц прекращается. В результате остаются непрореагировавшие с кислородом нанокластеры $\mathrm{Fe}_{3} \mathrm{O}_{4}$, расположенные в мезопорах в глубине МСМЧК, и образуется ядро состава $m \mathrm{SiO}_{2} / \mathrm{Fe}_{3} \mathrm{O}_{4}$ (рис. 1,c). Область, ограниченная сферами, одна из которых является внешней поверхностью ядра, а вторая - внешней поверхностью МСМЧК, представляет собой оболочку $m \mathrm{SiO}_{2} / \alpha-\mathrm{Fe}_{2} \mathrm{O}_{3}$. Таким образом, синтезированные нанокомпозитные частицы имеют гибридную структуру $m \mathrm{SiO}_{2} / \mathrm{Fe}_{3} \mathrm{O}_{4} @ m \mathrm{SiO}_{2} / \alpha-\mathrm{Fe}_{2} \mathrm{O}_{3}$ (рис. $1, c$ ).

Магнитные измерения МСМЧК, заполненных оксидами железа (рис. 4), выявляют поведение магнитного момента $I$ образцов в процессе перемагничивания, обусловленное однодоменными состояниями нанокластеров ферримагнетика $\mathrm{Fe}_{3} \mathrm{O}_{4}$, и демонстрируют изменение характера полевой зависимости $I(H)$ вследствие частичной трансформации $\mathrm{Fe}_{3} \mathrm{O}_{4}$ в антиферромагнетик $\alpha-\mathrm{Fe}_{2} \mathrm{O}_{3}$. Действительно, для каждого ферри- или ферромагнетика существует критический размер, ниже которого его частицы становятся однодоменными, и соответствующее ему значение размагничивающего поля $H_{c}$. В настоящей работе показано, что петля гистерезиса (рис. 4, кривая 1 ) магнитного момента демонстрирует характерное для однодоменного состояния ферримагнетика $\mathrm{Fe}_{3} \mathrm{O}_{4}$ [38] значение коэрцитивной силы при комнатной температуpe, соответствующее размеру частицы магнетита ниже критического однодоменного [39]. Уменьшение значения коэрцитивной силы $H_{c}$ и намагниченности насыщения (рис. 4, кривая 2) в частицах после частичного окисления $\mathrm{Fe}_{3} \mathrm{O}_{4}$ до $\alpha-\mathrm{Fe}_{2} \mathrm{O}_{3}$ отражает уменьшение как размеров однодоменных частиц магнетита, так и намагниченности насыщения в результате перехода части ферримагнитного магнетита в антиферромагнитный гематит.

\section{4. Заключение}

Разработан метод заполнения пор МСМЧК расплавом кристаллогидрата нитрата железа с одновременным термическим разложением кристаллогидрата, позволяющий формировать в порах нанокластеры $\alpha-\mathrm{Fe}_{2} \mathrm{O}_{3}$. В термодинамически равновесных условиях гематит восстановлен до магнетита. Степень заполнения мезопор оксидами железа составила $30 \%$ от общего объема пор в частицах. Синтезированные частицы, содержащие магнетит, отожжены в кислороде для превращения $\mathrm{Fe}_{3} \mathrm{O}_{4}$ обратно в $\alpha-\mathrm{Fe}_{2} \mathrm{O}_{3}$. Показано, что процесс окисления проходит не полностью, в результате образуются частицы со структурой ядро-оболочка, в которых в глубине МСМЧК мезопоры заполнены нанокластерами $\mathrm{Fe}_{3} \mathrm{O}_{4}$, а ближе к внешней поверхности частиц в мезопорах содержится $\alpha-\mathrm{Fe}_{2} \mathrm{O}_{3}$.

Характер и параметры полученных полевых зависимостей магнитного момента частиц до и после неполного окисления $\mathrm{Fe}_{3} \mathrm{O}_{4}$ в мезопорах служат экспериментальным подтверждением как образования нанокластеров магнетита, так и их частичной трансформации в гематит в результате проведенной технологической процедуры окисления.

В перспективе, синтезированные монодисперсные сферические частицы ядро-оболочка - $\mathrm{mSiO}_{2} /$ $\mathrm{Fe}_{3} \mathrm{O}_{4} @ m \mathrm{SiO}_{2} / \alpha-\mathrm{Fe}_{2} \mathrm{O}_{3}$ могут найти широкое применение в качестве МРТ контрастных средств и для магнитной гипертермии.

Исследования частично выполнены с использованием оборудования ЦКП „Материаловедение и диагностика в передовых технологиях“.

\section{Список литературы}

[1] A.G. Hu, Y.G. Tee, W.B. Lin. J. Am. Chem. Soc. 127, 12486 (2005).

[2] L. Huo, W. Li, L. Lu, H. Cui, S. Xi, J. Wang, B. Zhao, Y. Shen, Z. Lu. Chem. Mater. 12, 790 (2000).

[3] S. Kalantari, M. Yousefpour, Z. Taherian. Rare Met. 4, 1 (2016).

[4] S. Xuan, F. Wang, J.M.Y. Lai, K.W.Y. Sham, Y.X.J. Wang, S.-F. Lee, J.C. Yu, C.H.K. Cheng, K.C. Leung. Appl. Mater. Int. 3, 237 (2011).

[5] Y.V. Kolen'ko, M. Bañobre-López, C. Rodríguez-Abreu, E. Carbó-Argibay, A. Sailsman, Y. Piñeiro-Redondo, M.F. Cerqueira, D.Y. Petrovykh, K. Kovnir, O.I. Lebedev, J. Rivas. J. Phys. Chem. C 118, 8691 (2014).

[6] G. Srajer, L.H. Lewis, S.P. Bader, A.J. Epstein, C.S. Fadley. E.E. Fullerton, A. Hoffmann, J.B. Ortright, K.M. Krishnan, S.A. Majetich, T.S. Rahman, C.A. Ross, M.B. Salamon, I.K. Schuller, T.C. Schulthess, J.Z. Sun. J. Magn. Magn. Mater, 307, 1 (2006). 
[7] Д.А. Баранов, С.П. Губин. Радиоэлектроника. Наносистемы. Информационные технологии 1, 129 (2009).

[8] I. Ursachi, A. Stancu, A. Vasile. J. Colloid Interf. Sci. 377, 184 (2012).

[9] M. Fröba, R. Köhn, G. Bouffaud. Chem. Mater 11, 2858 (1999).

[10] S. Rostamizadeh, N. Shadjou, M. Azad, N. Jalali. Catalysis Commun. 26, 218 (2012).

[11] H.L. Ding, Y.X. Zhang, S. Wang, J.M. Xu, S.C. Xu, G.H. Li. Chem. Mater. 24, 4572 (2012).

[12] A. Lu, E.L. Salabas, F. Schuth. Angew. Chem. Int. Ed. 46, 1222 (2007).

[13] M.A. Gonzalez-Fernandez, T.E. Torres, M. Andrés-Vergés, R. Costo, P. Presa, C.J. Serna, M.P. Morales, C. Marquina, M.R. Ibarra, G.F. Goya. J. Solid State Chem. 182, 2779 (2009).

[14] Д.А. Курдюков, Д.А. Еуров, Е.Ю. Стовпяга, С.А. Яковлев, Д.А. Кириленко, В.Г. Голубев. ФТТ 56, 995 (2014).

[15] Y. Tian, D. Wu, X. Jia, B. Yu, S. Zhan. J. Nanomaterials 2011, 1 (2011).

[16] J.H. Lee, J. Jang, J. Choi, S.H. Moon, S.H. Noh, J. Kim, J. Kim, I. Kim, K.I. Park, J. Cheon. Nature Nanotech. 6, 418 (2011).

[17] M. Estrader, A. López-Ortega, I.V. Golosovsky, S. Estradé, A.G. Roca, G. Salazar-Alvarez, L. López-Conesa, D. Tobia, E. Winkler, J.D. Ardisson, W.A.A. Macedo, A. Morphis, M. Vasilakaki, K.N. Trohidou, A. Gukasov, I. Mirebeau, O.L. Makarova, R.D. Zysler, F. Peiró, M. Dolors-Baró, L. Bergström, J. Nogués. Nanoscale 7, 3002 (2015).

[18] Е.Ю. Трофимова, Д.А. Курдюков, Ю.А. Кукушкина, М.А. Яговкина, В.Г. Голубев. Физ. хим. стекла 37, 38 (2011).

[19] E.Yu. Trofimova, D.A. Kurdyukov, S.A. Yakovlev, D.A. Kirilenko, Yu.A. Kukushkina, A.V. Nashchekin, A.A. Sitnikova, M.A. Yagovkina, V.G. Golubev. Nanotechnology 24, 155601 (2013).

[20] V.Yu. Davydov, V.G. Golubev, N.F. Kartenko, D.A. Kurdyukov, A.B. Pevtsov, N.V. Sharenkova, P. Brogueira, R. Schwarz. Nanotechnology 11, 291 (2000).

[21] D.A. Eurov, D.A. Kurdyukov, D.A. Kirilenko, J.A. Kukushkina, A.V. Nashchekin, A.N. Smirnov, V.G. Golubev. J. Nanopart. Res. 17, 82 (2015).

[22] S.A. Grudinkin, S.F. Kaplan, N.F. Kartenko, D.A. Kurdyukov, V.G. Golubev. J. Phys. Chem. C 112, 17855 (2008).

[23] Д.А. Курдюков, А.Б. Певцов, А.Н. Смирнов, М.А. Яговкина, В.Ю. Григорьев, В.В. Романов, Н.Т. Баграев, В.Г. Голубев. ФТТ 58, 12 (2016).

[24] K. Wieczorek-Ciurowa, A.J. Kozak, J. Therm. Anal. Calorim. 58, 647 (1999).

[25] K.N. Orekhova, D.A. Eurov, D.A. Kurdyukov, V.G. Golubev, D.A. Kirilenko, V.A. Kravets, M.V. Zamoryanskaya. J. Alloys Comp. 678, 434 (2016).

[26] I.V. Golosovsky, I. Mirebeau, V.P. Sakhnenko, D.A. Kurdyukov, Y.A. Kumzerov. Phys. Rev. B 72, 144409 (2005).

[27] I.V. Golosovsky, I. Mirebeau, E. Elkaim, D.A. Kurdyukov, Y.A. Kumzerov. Eur. Phys. J. B 47, 55 (2005).

[28] D.A. Kurdyukov, D.A. Eurov, D.A. Kirilenko, J.A. Kukushkina, V.V. Sokolov, M.A. Yagovkina, V.G. Golubev. Microp. Mesop. Mater. 223, 225 (2016).

[29] Д.А. Курдюков, Д.А. Еуров, Е.Ю. Стовпяга, Д.А. Кириленко, С.В. Коняхин, А.В. Швидченко, В.Г. Голубев. ФТТ 58, 12 (2016).

[30] A.M. Jubb, H.C. Allen. Appl. Mater. Interf. 2, 2804 (2010).
[31] T.P. Martin, R. Merlin, D.R. Huffman, M. Cardona. Solid State Commun. 22, 565 (1977).

[32] K.F. McCarty. Solid State Commun. 68, 799 (1988).

[33] B. Verdes, I. Chira, M. Virgolichi, V. Moise. U.P.B. Sci. Bull. B 74, 257 (2012).

[34] U. Schwertmann, R.M. Cornell. Iron oxides in the laboratory. VCH Verlagsgesellschaft mbH, Weinhem (1991). 138 p.

[35] R.M. Cornell, R. Giovanoli, W. Shneider. J. Chem. Technol. 46, 115 (1989).

[36] Г. Шефер. Химические транспортные реакции. Мир, М. (1964). $194 \mathrm{c}$.

[37] G.M. Gajiev, D.A. Kurdyukov, V.V. Travnikov. Nanotechnology 17, 5349 (2006).

[38] C.V. Thach, N.H. Hai, N. Chau. J. Korean Phys. Soc. 52, 1332 (2008).

[39] Дж. Киршвик. Биогенный магнетит и магниторецепция. Мир, М. (1990). Т. 41.590 с. 